\title{
Biosynthesized gold nanoparticles supported on magnetic chitosan matrix as catalyst for reduction of 4-nitrophenol
}

\author{
Norfazreen Saffee, Mustaffa Shamsuddin", Khairil Juhanni Abd Karim \\ Department of Chemistry, Faculty of Science, Universiti Teknologi Malaysia, 81310 UTM Johor Bahru, Johor, Malaysia \\ *Corresponding author: mustaffa@kimia.fs.utm.my
}

\section{Article history}

Received 25 February 2019

Revised 23 April 2019

Accepted 30 May 2019

Published Online 25 June 2019

\section{Graphical abstract}

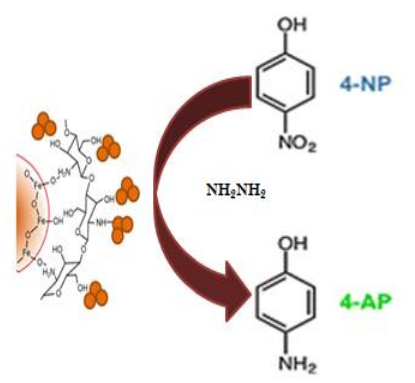

\begin{abstract}
The design and environmentally-safe synthesis of magnetically recoverable solid-supported metal nanoparticles with remarkable stability and catalytic performance have significant industrial importance. In the present study, we have developed an inexpensive bioinspired approach for assembling gold nanoparticles (AuNPs) in magnetic chitosan network under green, mild and scalable condition. AuNPs were well loaded on the surface of the magnetic support due to the presence of hydroxyl $(-\mathrm{OH})$ and amino $\left(-\mathrm{NH}_{2}\right)$ groups in chitosan molecules that provided the driving force for the complexation reaction with the $A u(I I I)$ ions. Reduction of the $A u(I I I)$ to $A u(0)$ was is achieved by using Melicope ptelefolia aqueous leaf extract. The synthesized magnetic chitosan supported biosynthesized Au nanocatalyst was characterized using Fourier Transform Infrared (FT-IR), Carbon, Hydrogen and Nitrogen (CHN), Transmission Electron Microscopy (TEM), X-Ray Diffraction (XRD) and Atomic Absorption Spectroscopy (AAS) analyses. FTIR spectrum of magnetic chitosan showed peaks at 1570 $\mathrm{cm}^{-1}$, which indicate for $\mathrm{N}-\mathrm{H}$ bending vibration and at $577 \mathrm{~cm}^{-1}$ which designates the $\mathrm{Fe}-\mathrm{O}$ bond. $\mathrm{CHN}$ analytical data further supported the coating of chitosan onto the magnetite. TEM analysis showed an amorphous layer around the magnetite core, proving the coating of chitosan on the magnetite surface and the average particle size of AuNPs calculated was $7.34 \pm 2.19 \mathrm{~nm}$. XRD analysis showed six characteristics peaks for magnetite, corresponding to lattice planes (220), (311), (400), (422), (511) and (440) in both the magnetite and magnetic chitosan samples (JCPDS file, PDF No. 65-3107). Meanwhile, XRD analysis of catalyst showed characteristic peaks of AuNPs at $2 \theta\left(38.21^{\circ}, 44.38^{\circ}\right.$, $62.2^{\circ}, 77.32^{\circ}$ and $80.76^{\circ}$ ), which correspond to (111), (200), (220), (311) and (222) lattice planes (JCPDS file, PDF No.04-0784). AAS analysis showed the loading of AuNPs as 5.4\%. The rate constant achieved for the reduction of 4-nitrophenol to 4-aminophenol in the presence of hydrazine hydrate using $10 \mathrm{mg}$ of catalyst was $0.0046 \mathrm{~s}^{-1}$. The magnetic chitosan supported AuNPs is effective as catalyst for the reduction of 4-nitrophenol.
\end{abstract}

Keywords: [Magnetic chitosan, Gold nanoparticles, Biosynthesis, Melicope ptelefolia, 4-nitrophenol]

(c) 2019 Penerbit UTM Press. All rights reserved

\section{INTRODUCTION}

Nanomaterials are receiving a considerable amount of attention from different fields of science because of their unique properties in which they differ from those of bulk materials. Among various metal nanoparticles, gold exhibits a significant potential of application in different areas like medical science, catalysis and drug delivery [1].

The most common method used for the synthesis of $\mathrm{Au}$ is the chemical reduction of $\mathrm{Au}$ (III) ions solution by using chemical reducing agent such as sodium borohydride $\left(\mathrm{NaBH}_{4}\right)$ and citrate but such reducing agents are toxic and hazardous [2]. Due to these problems, there is a need to develop environmental friendly process for gold nanaoparticles (AuNPs) production that does not involve toxic chemicals in the synthesis process. Among different biological systems employed for AuNPs synthesis, plants extract has several advantages as compared to fungi and bacteria, as it is easily available, non-toxic and eliminate the use of complicated techniques for cell cultures [3].
Melicope ptelefolia is a plant species belonging to the family Rutaceae. It is a medicinal and widely grown plant in Malaysia and is locally known as 'Tenggek Burung'. It is a popular salad and consumed raw by the Malay community. Leaves of this plant have its own benefits such as to revitalize the body and to release tension. In addition, its leaves have been reported to help in controlling and reducing high blood pressure and diabetes mellitus if consumed regularly [4]. This plant can be used as a reducing agent in this research due to the presence of biomolecules in its leaf extract. These biomolecules are responsible to reduce metal ions to form metal atom [5]. As in [6], Hygrophila spinosa aqueous leaf extract has been used as reducing agent for $\mathrm{HAuCl}_{4}$ to obtain gold nanoparticles in order to apply in pharmaceutical industry.

Chitosan (CS), a derivative biopolymer obtained from the deacetylation of chitin, occurs naturally and abundantly from the exoskeletons of insects, crustaceans' shells and fungi cellular walls. Chitosan is one of the bioabsorbable and non-toxic polymers, which is processed in different biofunctionalities. Recently, chitosan, which is used as an adsorbent, is attracting a lot of attention due to its hydroxyl 
and amino functional groups that show high potential for adsorption of metal ions [7].

Magnetic separation technique has some advantages, such as high efficiency and cost-effectiveness. In this regard, magnetite $\left(\mathrm{Fe}_{3} \mathrm{O}_{4}\right)$ has been widely used as magnetic material due to its excellent magnetic properties, chemical stability and biocompatibility. Thus, by using $\mathrm{Fe}_{3} \mathrm{O}_{4}$ as the main support, the catalyst can be easily separated from the reaction media with the aid of an external magnet, leading to fast and efficient recovery route [8].

4-nitrophenol is a common organic waste water pollutant which is widely used in the preparation of pesticides, explosives and pharmaceutical industries. This compound poses significant health risk due to its carcinogenic activities. On the other hand, 4-aminophenol is an important intermediate for the production of pharmaceuticals substances, photographic materials and rubber materials [9].

In the present study, we have developed an inexpensive bioinspired approach for decorating small gold nanoparticles (AuNPs) in a magnetic chitosan network using Melicope ptelefolia leaf extract under green, mild and scalable condition. Preparation of magnetic chitosan matrix is significant due to prevent agglomeration between metal-metal atoms after being reduced. Structural features as well as catalytic performance of the prepared hybrid nanocomposite have been investigated in the reduction of 4-nitrophenol to 4-aminophenol.

\section{EXPERIMENTAL}

\section{Materials}

All glasswares were washed thoroughly with deionised water and dried overnight in the oven before being used for experiment. Deionised water was used throughout this study. Commercial grade solvents were distilled before being used. All chemicals were obtained commercially from Sigma-Aldrich and were used as received without further purifications. Melicope ptelefolia (Tenggek Burung) leaves were purchased from a local market in Johor Bahru.

\section{Synthesis of magnetite $\left(\mathrm{Fe}_{3} \mathrm{O}_{4}\right)$ nanoparticles}

$\mathrm{Fe}_{3} \mathrm{O}_{4}$ was prepared according to literature method with some modifications [8]. A mixture of iron(III) chloride hexahydrate $\left(\mathrm{FeCl}_{3} .6 \mathrm{H}_{2} \mathrm{O}\right)(2.7 \mathrm{~g}, 10 \mathrm{mmol})$ and iron(II) chloride tetrahydrate $\left(\mathrm{FeCl}_{2} .4 \mathrm{H}_{2} \mathrm{O}\right)(1.0 \mathrm{~g}, 5 \mathrm{mmol})$ was dissolved in deionised water $(130$ $\mathrm{mL})$ under $\mathrm{N}_{2}$ flow. Ammonium hydroxide $\left(\mathrm{NH}_{4} \mathrm{OH}\right)(11 \mathrm{~mL}, 28 \% \mathrm{v} / \mathrm{v})$ was added under rapid mechanical stirring $(700 \mathrm{rpm})$. The resultant solution was heated to $60{ }^{\circ} \mathrm{C}$ and stirred for $1 \mathrm{~h}$ under $\mathrm{N}_{2}$ flow. The reaction mixture was let to cool at room temperature before washing it using deionised water twice. The product formed was collected by using external magnet and redispersed in trisodium citrate $(200 \mathrm{~mL}, 0.3$ M). Then, the solution was further heated at $80{ }^{\circ} \mathrm{C}$ for $1 \mathrm{hr}$. The precipitate formed $\left(\mathrm{Fe}_{3} \mathrm{O}_{4}\right)$ was collected by using external magnet and washed with acetone. The product was kept in a desiccator for further reaction.

\section{Synthesis of magnetic chitosan $\left(\mathrm{Fe}_{3} \mathrm{O}_{4}-\mathrm{CS}\right)$ nanoparticles}

Magnetic chitosan $\left(\mathrm{Fe}_{3} \mathrm{O}_{4}-\mathrm{CS}\right)$ was prepared following the method as reported with some modifications [9]. $\mathrm{Fe}_{3} \mathrm{O}_{4}(0.5 \mathrm{~g})$ was dispersed in deionised water $(150 \mathrm{~mL})$ while chitosan $(75 \%-85 \%$ deacytelated) flakes $(0.25 \mathrm{~g})$ were dissolved separately in acetic acid $(70 \mathrm{~mL}, 2 \mathrm{wt} \%)$ with continuous stirring. Both solutions were mixed under vigorous stirring for $1 \mathrm{~h}$. Then, the resultant solution was transferred quickly into a beaker. The product obtained was collected by using external magnet, washed with acetone and kept in a desiccator for further use.

\section{Preparation of Melicope ptelefolia leaf extracts solution}

Fresh Melicope ptelefolia leaves were washed thoroughly with deionised water to remove any dust or impurities and dried at room temperature for 1-2 weeks. The dried leaves were ground into powder using an electrical blender. Melicope ptelefolia leaf powder (4 g) was extracted with deionised water $(200 \mathrm{~mL})$ in a Soxhlet apparatus for $8 \mathrm{~h}$ The resultant leaf extract was transferred into a porcelain crucible and slowly heated to remove the solvent. The dried, powdered solid obtained was kept in a vacuum desiccator for further use. A $10 \% \mathrm{w} / \mathrm{v}$ leaf extract solution was prepared by dissolving $10 \mathrm{mg}$ of dried powder in $100 \mathrm{~mL}$ deionised water.

\section{Immobilization of $\mathrm{Au}(\mathrm{III})$ ions onto $\mathrm{Fe}_{3} \mathrm{O}_{4}-\mathrm{CS}$ nanoparticles}

Tetrachloroauric(III) acid $\left(\mathrm{HAuCl}_{4}\right)(0.3 \mathrm{mM}, 25 \mathrm{~mL})$ was mixed with $\mathrm{Fe}_{3} \mathrm{O}_{4}-\mathrm{CS}(30 \mathrm{mg})$ in a centrifuge tube. The mixture was shaken mechanically $(480 \mathrm{rpm})$ for about $24 \mathrm{~h}$ at room temperature. The product $\left(\mathrm{Fe}_{3} \mathrm{O}_{4}-\mathrm{CS}-\mathrm{Au}(\mathrm{III})\right)$ was collected by an external magnet, washed with deionised water and allowed to dry. The separated solution was analyzed by Atomic Absorption Spectroscopy (AAS).

\section{Bioreduction of immobilized $\mathrm{Au}(\mathrm{III})$ to $\mathrm{Au}(0)$ nanoparticles using Melicope ptelefolia leaf extract}

$\mathrm{Fe}_{3} \mathrm{O}_{4}-\mathrm{CS}-\mathrm{Au}$ (III) obtained from the previous reaction was directly treated with Melicope ptelefolia leaf extract solution $(12 \mathrm{~mL}, 10 \%$ $\mathrm{w} / \mathrm{v})$. The mixture was shaken for $2 \mathrm{~h}$ at room temperature. The final product $\left(\mathrm{Fe}_{3} \mathrm{O}_{4}-\mathrm{CS}-\mathrm{AuNPs}\right)$ was collected using an external magnet, washed with deionised water and dried in the desiccator for further use.

\section{Catalytic reduction of 4-nitrophenol to 4-aminophenol}

Catalytic reduction of 4-nitrophenol was performed following literature method [10]. Hydrazine hydrate $(0.375 \mathrm{mM}, 1.6 \mathrm{~mL})$ was added into 4-nitrophenol $(0.125 \mathrm{mM}, 1.6 \mathrm{~mL})$. Then, the $\mathrm{Fe}_{3} \mathrm{O}_{4}-\mathrm{CS}$ AuNPs $(10 \mathrm{mg})$ catalyst was added into the reaction mixture with stirring. The UV-vis absorption spectrum of the reaction mixture was recorded with time to monitor the change in absorption intensity of the reaction mixture in the scanning range of $200-500 \mathrm{~nm}$.

\section{RESULTS AND DISCUSSION}

$\mathrm{Fe}_{3} \mathrm{O}_{4}$-CS-AuNPs was synthesised via a simple and inexpensive method by the immobilisation of AuNPs on the magnetic chitosan support using Melicope ptelefolia leaf extract in this work. The leaf extract extract acted as a reducing and stabilizing agent in the preparation of AuNPs on the surface of the magnetic chitosan. The presence of biomolecules such as $p$ - $O$-geranylcoumaric acid and 2,4,6trihydroxy-3-farnesylgeranylacetophenone in the Melicope ptelefolia leaf extract are believed to be responsible in the reduction of $\mathrm{Au}(\mathrm{III})$ to $\mathrm{Au}(0)[11]$.

FTIR spectroscopic analysis was carried out to identify functional groups presented in $\mathrm{CS}, \mathrm{Fe}_{3} \mathrm{O}_{4}, \mathrm{Fe}_{3} \mathrm{O}_{4}-\mathrm{CS}$ and $\mathrm{Fe}_{3} \mathrm{O}_{4}-\mathrm{CS}$-AuNPs. The FTIR spectra of the samples were as presented in Figure 1.

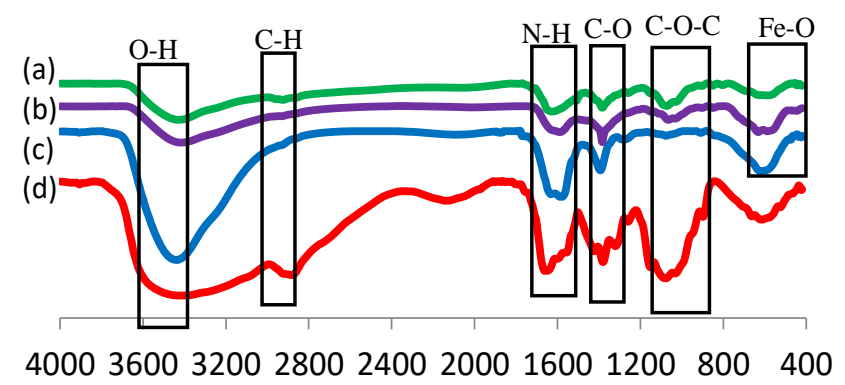

Figure 1 FTIR absorption spectra of (a) $\mathrm{Fe}_{3} \mathrm{O}_{4}$-CS, (b) $\mathrm{Fe}_{3} \mathrm{O}_{4}$-CSAuNPs, (c) $\mathrm{Fe}_{3} \mathrm{O}_{4}$ and (d) CS.

Absorption bands at $3401 \mathrm{~cm}^{-1}$ and $3370 \mathrm{~cm}^{-1}$ observed in the IR spectrum of magnetite and magnetic chitosan are indicative of $\mathrm{OH}$ group. The presence of an $\mathrm{OH}$ band in the magnetite spectrum may be due to trace of water during its preparation. The appearance of characteristic bands at $591 \mathrm{~cm}^{-1}$ and $580 \mathrm{~cm}^{-1}$ in the IR spectrum of magnetite and magnetic chitosan is due to Fe-O bond. The FTIR spectrum of chitosan was characterized by the following absorption bands; the $(\mathrm{NH})$ of backbone polymer arose around $1650 \mathrm{~cm}^{-1}$, (C-O) of primary alcoholic group at $1380 \mathrm{~cm}^{-1}$, and the $(\mathrm{C}-\mathrm{H})$ at $2893 \mathrm{~cm}^{-1}$. The shift of the $\mathrm{Fe}-\mathrm{O}$ stretching frequency from $591 \mathrm{~cm}^{-1}$ in magnetite to $580 \mathrm{~cm}^{-1}$ in the magnetic chitosan and of the N-H bending vibration from $1650 \mathrm{~cm}^{-1}$ to $1612 \mathrm{~cm}^{-1}$ strongly suggested the binding of $\mathrm{Fe}$ to 
the $\mathrm{NH}_{2}$ groups of chitosan. The band appeared at $1386 \mathrm{~cm}^{-1}$ in the IR of magnetic chitosan is assigned to the $\mathrm{C}-\mathrm{O}$ of alcoholic group of chitosan. Further, the peak around $2925 \mathrm{~cm}^{-1}$ which corresponded to the $\mathrm{C}-\mathrm{H}$ stretching band of chitosan was observed in the IR spectra of both chitosan and magnetic chitosan, strongly suggesting the successful coating of the magnetite surface with chitosan. The IR spectrum of $\mathrm{Fe}_{3} \mathrm{O}_{4}$-CS-AuNPs showed similar absorption bands as the $\mathrm{Fe}_{3} \mathrm{O}_{4}-\mathrm{CS}$, which probably suggesting that AuNPs had successfully anchored on the $\mathrm{Fe}_{3} \mathrm{O}_{4}-\mathrm{CS}$ layer. This observation is in agreement with the findings of Liu et al [12].

The XRD patterns of $\mathrm{Fe}_{3} \mathrm{O}_{4}$ and $\mathrm{Fe}_{3} \mathrm{O}_{4}-\mathrm{CS}$ were shown in Figures 2(a) and 2(b) respectively. Six characteristic peaks were observed in both samples for $\mathrm{Fe}_{3} \mathrm{O}_{4}$ (JCPDS file, PDF No. 65-3107) which corresponded to crystal planes of (220), (311), (400), (511), and (440). Weak and broad diffraction lines were observed in the diffractogram of both samples probably due to very low amount of samples and small crystallite size. Meanwhile, XRD analysis of $\mathrm{Fe}_{3} \mathrm{O}_{4}-\mathrm{CS}$-AuNPs in Figure 2(c) showed five characteristics peaks of AuNPs (JCPDS file, PDF No. 04-0784), corresponding to crystal planes of (111), (200), (220), (311) and (222), which are consistent with literature values [13]. Besides, there were also distinctive peaks of $\mathrm{Fe}_{3} \mathrm{O}_{4}$ seen in the diffractogram of $\mathrm{Fe}_{3} \mathrm{O}_{4}-\mathrm{CS}-\mathrm{AuNPs}$, showing the existence of the magnetite as the core.

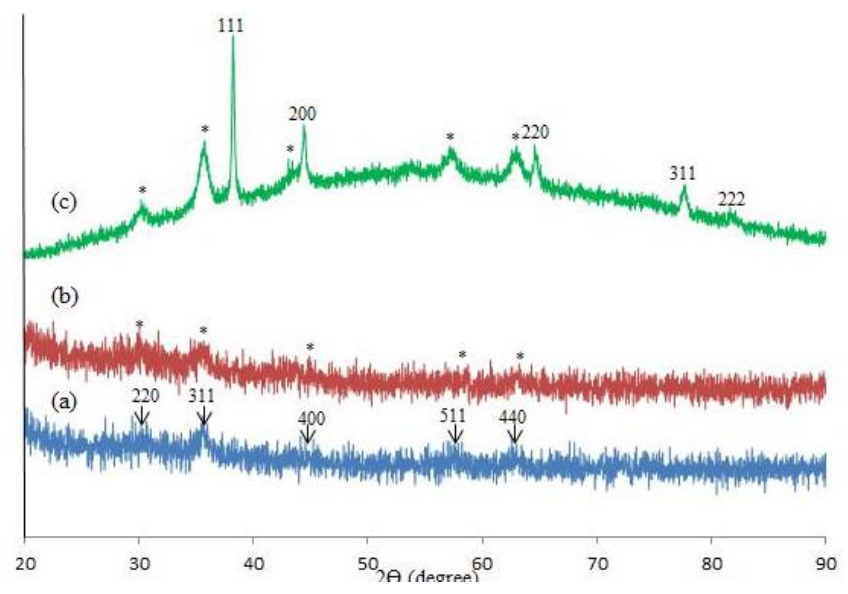

Figure 2 XRD pattern of (a) $\mathrm{Fe}_{3} \mathrm{O}_{4}$, (b) $\mathrm{Fe}_{3} \mathrm{O}_{4}$-CS and (c) $\mathrm{Fe}_{3} \mathrm{O}_{4}$-CSAuNPs.

Meanwhile, TEM micrographs for $\mathrm{Fe}_{3} \mathrm{O}_{4}$ and $\mathrm{Fe}_{3} \mathrm{O}_{4}-\mathrm{CS}$ with same magnification were shown in Figure 3. The chitosan layer could be seen formed on the surface of the $\mathrm{Fe}_{3} \mathrm{O}_{4}$ nanoparticles as shown in Figure 3 (b). In this figure, the parallel lines crossing the particle image represented the crystal planes of nanoparticles. Under careful examination, these lines did not extend till the edges of magnetite nanoparticles. The remaining area (bounded by the red circle) that did not include the crystal planes would correspond to an amorphouschitosan layer. Similar findings have been reported by Osuna et al in their work on chitosan coated magnetic nanoparticles [10].

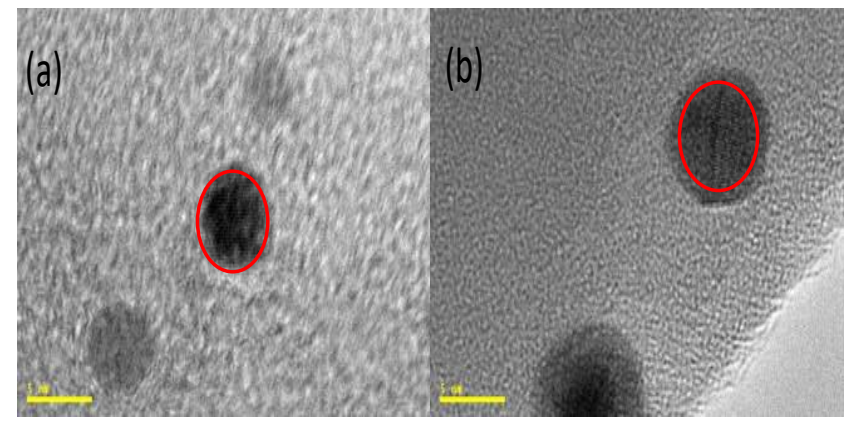

Figure 3 TEM images of (a) $\mathrm{Fe}_{3} \mathrm{O}_{4}$ and (b) $\mathrm{Fe}_{3} \mathrm{O}_{4}$-CS with same scale, $5 \mathrm{~nm}$.
Table $1 \mathrm{CHN}$ analysis of $\mathrm{Fe}_{3} \mathrm{O}_{4}$ - $\mathrm{CS}$.

\begin{tabular}{|c|c|c|c|}
\hline \multirow{2}{*}{ Sample } & \multicolumn{3}{|c|}{ Elements (\%) } \\
\cline { 2 - 4 } & $\mathrm{C}$ & $\mathrm{H}$ & $\mathrm{N}$ \\
\hline $\mathrm{Fe}_{3} \mathrm{O}_{4}$-CS & 10.28 & 2.31 & 1.18 \\
\hline
\end{tabular}

CHN elemental analytical data of $\mathrm{Fe}_{3} \mathrm{O}_{4}-\mathrm{CS}$ (Table 1), shows the existence of nitrogen element which further supports the coating of chitosan onto $\mathrm{Fe}_{3} \mathrm{O}_{4}$. Meanwhile Table 2 shows the AAS analytical data indicating the actual $\mathrm{Au}$ loading on the $\mathrm{Fe}_{3} \mathrm{O}_{4}$-CS surface of $5.4 \%$ which is in close agreement with the calculated values, suggesting that chitosan had acted as an effective support for $\mathrm{Au}(0)$ nanoparticles, binding through its $-\mathrm{OH}$ and $-\mathrm{NH}_{2}$ groups.

Table 2 AAS analysis of $\mathrm{Fe}_{3} \mathrm{O}_{4}$-CS-AuNPs.

\begin{tabular}{|c|c|c|}
\hline Au loading & Calculated & Experimental \\
\hline$(\%)$ & 6.0 & 5.4 \\
\hline
\end{tabular}

Figure 4 shows TEM image of $\mathrm{Fe}_{3} \mathrm{O}_{4}$-CS-AuNPs which showed good dispersity of the AuNPs which were mostly spherical with less agglomeration. This probably suggesting that the chitosan matrix is successful in preventing agglomeration of the AuNPs. Figure 4(b) shows that the d-spacing of AuNPs calculated was $0.23 \mathrm{~nm}$ which is in very good agreement with literature data [14]. Based on the imageJ software, the mean particle size calculated from 20 AuNPs (Figure 4(c)) was $7.3 \mathrm{~nm}$.
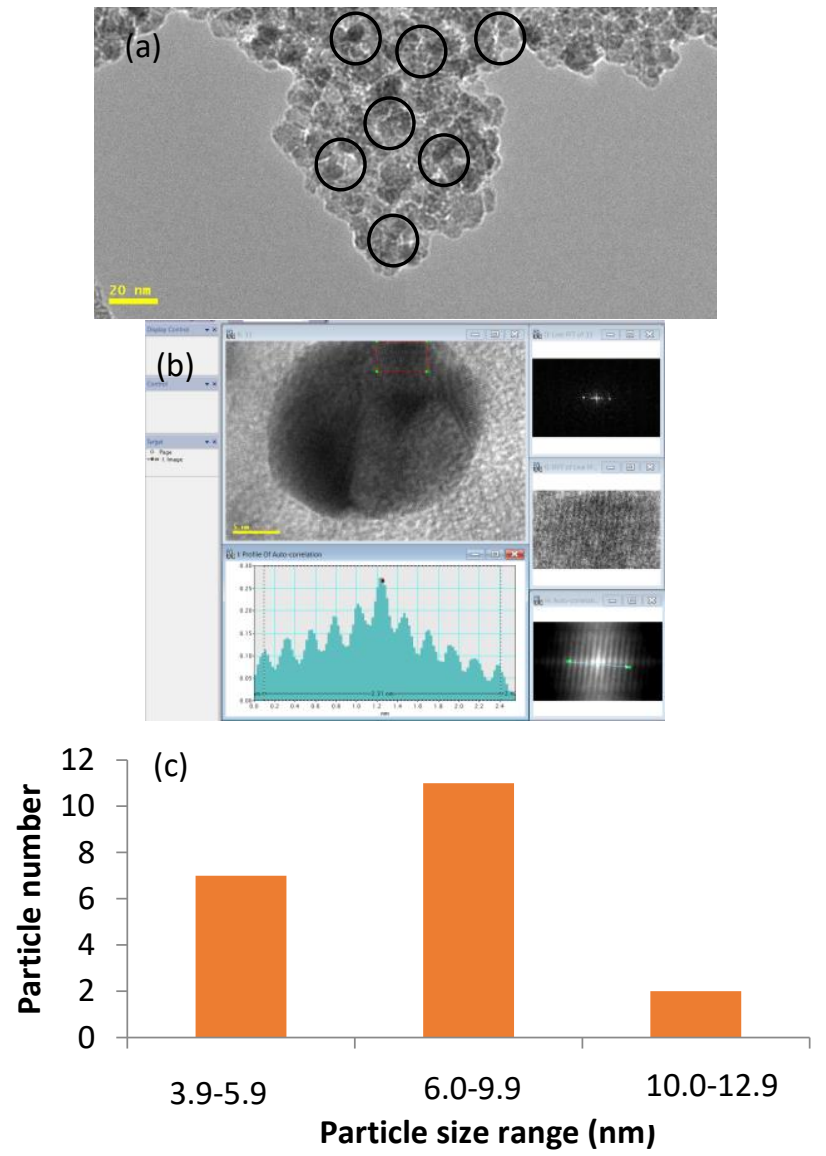

Figure 4 (a)TEM image of $\mathrm{Fe}_{3} \mathrm{O}_{4}$-CS-AuNPs with $20 \mathrm{~nm}$ scale (b) dspacing of AuNPs (c) Particles size distribution of AuNPs.

The catalytic activity of $\mathrm{Fe}_{3} \mathrm{O}_{4}-\mathrm{CS}$-AuNPs was investigated in the reduction of 4-nitrophenol in the presence of $\mathrm{N}_{2} \mathrm{H}_{4}$ and shown in Figure 5. The UV-visible spectrum of an aqueous solution of 4nitrophenol (Figure 5(a)) showed a maximum absorption at $314 \mathrm{~nm}$. 
After the addition of hydrazine hydrate, a red shift was observed with the maximum absorption at $398 \mathrm{~nm}$, indicating the formation of 4nitrophenolate ions. After the addition of the $\mathrm{Fe}_{3} \mathrm{O}_{4}-\mathrm{CS}$-AuNPs catalyst (Figure 5(c)), a gradual decrease in the absorbance for the 4nitrophenolate ions peak at $398 \mathrm{~nm}$ was observed along with gradual increase of a new absorbance at $313 \mathrm{~nm}$, indicating the formation of 4 aminophenol. Complete reduction of 4-nitrophenol occurred within 40 $\min$.

The reduction of 4-nitrophenol to 4-aminophenol was also monitored in the absence of $\mathrm{Fe}_{3} \mathrm{O}_{4}$-CS-AuNPs catalyst. As can be seen in Figure 5(b), the peak at $398 \mathrm{~nm}$ showed almost no change in intensity after $40 \mathrm{~min}$ of reaction time, hence suggesting that no significant reduction has occurred without the presence of biostablised $\mathrm{Fe}_{3} \mathrm{O}_{4}-\mathrm{CS}$ AuNPs catalyst.
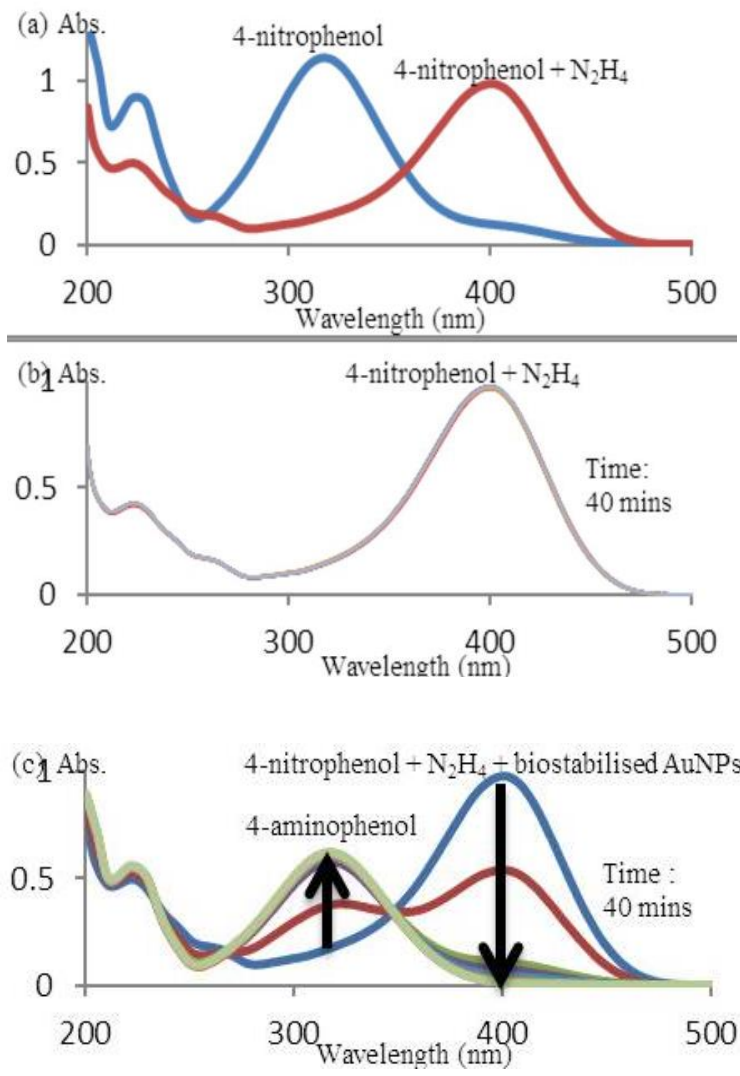

Figure 5 (a) UV-visible spectra of 4-nitrophenol and after the addition of $\mathrm{N}_{2} \mathrm{H}_{4}$ (b) UV-visible spectrum of (4-nitrophenol $+\mathrm{N}_{2} \mathrm{H}_{4}$ ) in 40 minutes time of reaction (c) UV-visible spectra of (4-nitrophenol $+\mathrm{N}_{2} \mathrm{H}_{4}+$ biostabilised AuNPs) in 40 minutes time of reaction.

The catalytic reaction was studied in excess of $\mathrm{N}_{2} \mathrm{H}_{4}$ concentration as compared to 4-nitrophenol. Thus, the concentration of $\mathrm{N}_{2} \mathrm{H}_{4}$ was considered as constant and the reaction rate constant $\left(\mathrm{k}_{\mathrm{a}}\right)$ of the reduction was-only depended on the 4-nitrophenol concentration. Hence, the reaction was assumed to follow the pseudo first-order kinetics and calculated by using the following kinetic equation:

$-\mathrm{k}_{\mathrm{a}}=\ln \left(\mathrm{C}_{\mathrm{t}} / \mathrm{C}_{0}\right)=\ln \left(\mathrm{A}_{\mathrm{t}} / \mathrm{A}_{0}\right)$

where $C_{t}$ and $A_{t}$ are the concentration and absorption of 4-nitrophenol at time ( $\mathrm{t}$ ) while $\mathrm{C}_{0}$ and $\mathrm{A}_{0}$ are the concentration and absorption of 4nitrofenol at the initial time of the reaction [15]. The rate constant $\left(\mathrm{k}_{\mathrm{a}}\right)$ was calculated from the slope of the plot of $\ln \left(A_{t} / A_{0}\right)$ versus the reaction time $(\mathrm{t})$ as displayed in Figure 6. The rate constant obtained from the reaction using $10 \mathrm{mg}$ AuNPs and 5.4\% Au loading of $\mathrm{Fe}_{3} \mathrm{O}_{4}$ CS-AuNPs was $0.0046 \mathrm{~s}^{-1}$.

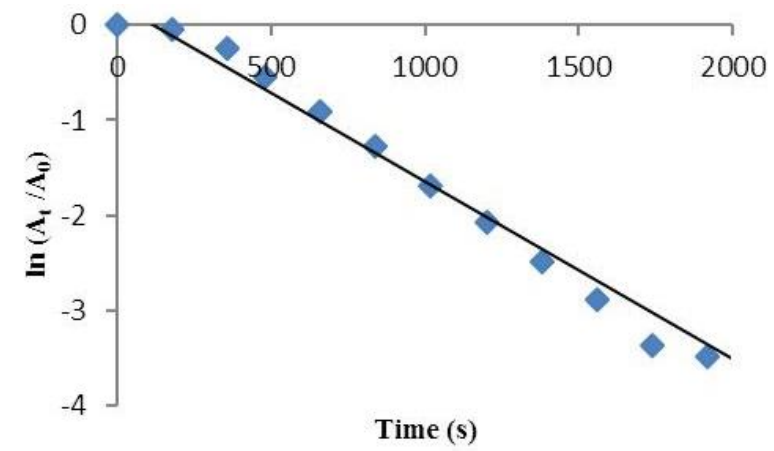

Figure 6 Plot of $\ln \left(A t / A_{0}\right)$ versus time $(t)$ for the reduction of 4-nitrophenol by using $10 \mathrm{mg}$ AuNPs and $5.4 \%$ Au loading of $\mathrm{Fe}_{3} \mathrm{O}_{4}$-CSAuNPs.

\section{CONCLUSION}

In summary, biostabilised AuNPs have been successfully supported onto the $\mathrm{Fe}_{3} \mathrm{O}_{4}-\mathrm{CS}$ support. The use of $\mathrm{Fe}_{3} \mathrm{O}_{4}-\mathrm{CS}$ as catalyst support provides a good dispersity of the AuNPs catalyst with less agglomeration. The biosynthesised AuNPs are mostly spherical with an average size of $7.3 \mathrm{~nm}$. The magnetic chitosan supported biostabilised AuNPs showed good catalytic activity in the reduction of 4-nitrophenol to 4-aminophenol in the presence of $\mathrm{N}_{2} \mathrm{H}_{4}$ where the reduction was complete in 40 minutes with the rate of reaction of $0.0046 \mathrm{~s}^{-1}$. The synthesised magnetic AuNPs catalyst can also be tested in the other organic transformations such catalytic oxidation of benzylic and allylic alcohols, reduction of nitroaromatics and epoxidations.

\section{ACKNOWLEDGEMENT}

This work was financially supported by Ministry of Higher Education Malaysia and Universiti Teknologi Malaysia under FRGS funding vot no. 4F779

\section{REFERENCES}

[1] Khan, I., Saeed, K., Khan, I. (2017). Nanoparticles: Properties, applications and toxicities. Arabian Journal of Chemistry, 05 (11), 1-24.

[2] Taha, A., Shamsuddin, M., Alizadeh, A. (2014). Characteristics study on biosynthesized au nanoparticles supported onto cross-link chitosan beads. Journal of Applied Science, 14(21), 2843-2848.

[3] Gardea-Torresdey, Gomez, J. L. E., Peralta-Videa, J. R., Parsons, J. G., Troiani, H., Jose-Yacaman, M. (2003). Alfalfa sprouts: A natural source for the synthesis of silver nanoparticles. Langmuir, 19, 1357-1361.

[4] Ab. Karim, M. S., Nasouddin, S. S., Othman, M., Mohd Adzahan, N., Hussin, S. R., Khozirah, S. (2011). Consumers' knowledge and perception towards Melicope ptelefolia (Daun Tenggek Burung): A preliminary qualitative study. International Food Research Journal, 18(4):1481.

[5] Makarov, V. V., Love, A. J., Sinitsyna, O. V., Makarova, S. S., Yaminsky, I. V., Taliansky, M. E., Kalinina, N. O. (2013). "Green" Nanotechnologies: Synthesis of metal nanoparticles using plants. Acta Naturae, 6(20), 35-44

[6] Koperuncholan, M. (2015). Bioreduction of chloroauric acid (HAuCl4) for the synthesis of gold nanoparticles (GNPs): A special empathies of pharmacological activity. International Journal of Phytopharmacy, 5 (4), $72-80$

[7] Ahmad, M., Ahmed, S., Swami, B. L., Ikram, S. (2015). Adsorption of heavy metal ions: Role of chitosan and cellulose for water treatment. International Journal of Pharmacognosy, 2(6), 280-289.

[8] Parandhaman, T., Pentela, N., Ramalingam, B., Samanta, D., Das, S. K. (2017). Metal nanoparticle loaded magnetic-chitosan microsphere: water dispersible and easily separable hybrid metal nano-biomaterial for catalytic applications. ACS Sustainable Chemistry \& Engineering, 5(1), 489-501.

[9] Mehmood, S., Janjua, N. K., Saira, F., Fenniri, H. (2016). AuCl @ Pt nanoalloys for catalytic application reduction of 4-nitrophenol. Journal of Spectroscopy, 6210794, 1-8.

[10] Osuna, Y., Gregorio-Jauregui, K. M., Gaona-Lozano, J. G., Ilyna, A., Barriga-Castro, E. D., Saade, H., Lopez, R. G. (2012). Chitosan-coated 
magnetic nanoparticles with low chitosan content prepared in one-step. Journal of Nanomaterials, 327562.

[11] Yang, D. J., Hu, S., Fu. (2009). Controlled synthesis of magnetite-silica nanocomposites via a seeded sol-gel approach. The Journal of Physical Chemistry, 113(18), 7646-7651.

[12] Safari, J., Javadian, L. (2014). Chitosan decorated $\mathrm{Fe}_{3} \mathrm{O}_{4}$ nanoparticles as a magnetic catalyst in the synthesis of Phenytoin derivatives. RSC Advances, 4, 48973-48979.

[13] Borhamdin, S., Shamsuddin, M., Alizadeh, A. (2016). Biostabilised icosahedral gold nanoparticles: Synthesis, cyclic voltammetric studies and catalytic activity towards 4-nitrophenol reduction. Journal of Experimental Nanoscience, 11(7), 518-530.

[14] Abas, F., Shaari, K., Israf, D., A., Syafri, S., Zainal, Z., Lajis, N. H. (2010). LC-DAD-ESI-MS analysis of nitric oxide inhibitory fractions of tenggek burung (Melicope ptelefolia Champ. ex Benth.). Journal of Food Composition and Analysis, 23, 107-112.

[15] Liu, X., L., Yang, X., Xin, H., Y., Tang, X., P., Weng, L., J., Han, Y., Y., Geng, D. (2016). Ecofriendly Fabrication of $\mathrm{Au} / \mathrm{Fe}_{3} \mathrm{O}_{4}$-Chitosan Composites for Catalytic Reduction of Methyl Orange. Digest Journal of Nanomaterials and Biostructures, 11, 337-348.

[16] Lu, X., Song, Y., Zhu, A., Wu, F., Song, Y. (2012). Synthesis of gold nanoparticles using cefopernazone as a stabilizing reagent and its application. International Journal of Electrochemical Science, 7, 1123611245 .

[17] Sapkota, K., Han, S. S. (2017). A novel environmentally sustainable synthesis Of $\mathrm{Au}-\mathrm{Ag} @ \mathrm{Agcl}$ nanocomposites and their application as an efficient and recyclable catalyst for quinoline synthesis. New Journal of. Chemistry, 41, 5395-5402.

[18] Zayed, M. F., Eisa W. H. (2014). Phoenix dactylifera L. leaf extract phytosynthesized gold nanoparticles; controlled synthesis and catalytic activity. Spectrochim Acta A, 121, 238-244. 